\title{
Geochemical speciation and pollution assessment of heavy metals in surface sediments from Nansi Lake, China
}

\author{
Liyuan Yang • Longfeng Wang • Yunqian Wang • \\ Wei Zhang
}

Received: 2 December 2014 / Accepted: 26 March 2015 /Published online: 17 April 2015

(C) Springer International Publishing Switzerland 2015

\begin{abstract}
Sixteen surface sediment samples were collected from Nansi Lake to analyze geochemical speciation of heavy metals including $\mathrm{Cd}, \mathrm{As}, \mathrm{Pb}, \mathrm{Cr}$, and $\mathrm{Zn}$, assess their pollution level, and determine the spatial distribution of the non-residual fraction. Results showed that $\mathrm{Cd}$ had higher concentrations in water-soluble and exchangeable fractions. As and $\mathrm{Pb}$ were mainly observed as humic acid and reducible fractions among the non-residual fractions, while $\mathrm{Cr}$ and $\mathrm{Zn}$ were mostly locked up in a residual fraction. The mean pollution index $\left(P_{\mathrm{i}}\right)$ values revealed that the lower lake generally had a higher enrichment degree than the upper lake. $\mathrm{Cd}$ (2.73) and As (2.05) were in moderate level of pollution, while the pollution of $\mathrm{Pb}$ (1.80), $\mathrm{Cr}$ (1.27), and $\mathrm{Zn}$ (1.02) appeared at low-level pollution. The calculated pollution load index (PLI) suggested the upper lake suffered from borderline moderate pollution, while the lower lake showed moderate to heavy pollution. Spatial principle component analysis showed that the first principal component (PC1) including $\mathrm{Cd}$, As, and $\mathrm{Pb}$ could explain $56.18 \%$ of the non-residual fraction. High values of PC1 were observed mostly in the southern part of
\end{abstract}

L. Yang $(\bowtie) \cdot$ Y. Wang $\cdot$ W. Zhang

Department of Resources and Environment, University of Jinan, Jinan 250022, China

e-mail: youngliyuan@126.com

\section{Wang}

Key Laboratory of Water Cycle and Related Land Surface Processes, Institute of Geographic Sciences and Natural Resources Research, Chinese Academy of Sciences, Beijing 100101, China
Weishan Lake, which indicated greater bioavailability and toxicity of $\mathrm{Cd}, \mathrm{As}$, and $\mathrm{Pb}$ in this area.

Keywords Nansi Lake · Heavy metals · Speciation . Pollution level $\cdot$ Spatial distribution

\section{Introduction}

The study of sediments plays an important role in providing proof of contamination, because sediments act as both a carrier and a possible source of contaminants in aquatic systems (Chen et al. 2008). Heavy metal contamination has attracted a great deal of attentions because of its toxicity, abundance, and persistence in the environment. An evaluation of the total heavy metal load following a strong acid digestion of the sediments may be useful as a global index of contamination, but it provides little indication of their bioavailability, mobility, and reactivity in sediments (Shrivastava and Banerjee 2004; Varol 2011). The sequential extraction technique is recognized as a useful method for gaining information on the manner of toxicity, bioavailability, and mobilization of heavy metals despite its poor selectivity (Feng et al. 2009; Karbassi et al. 2006). The toxicity of metals depends especially on their geochemical speciation rather than their total content (Liu et al. 2008). Therefore, the fractionation of heavy metals must be considered when investigating heavy metal contamination. 
In recent decades, Nansi Lake and its tributaries have been contaminated by the untreated effluents from industrial and municipal activities, runoff from mining sites and agricultural lands, and deposition of air pollutants (Wang et al. 2012). Therefore, the present study was conducted to meet the following objectives: (i) to analyze geochemical speciation of heavy metals in surface sediments of Nansi Lake; (ii) to analyze the level of heavy metal pollution in surface sediments using pollution index $\left(P_{\mathrm{i}}\right)$ and pollution load index (PLI); and (iii) to explore the spatial distribution of the non-residual fraction of studied heavy metals using principal component analysis.

\section{Materials and methods}

\section{Study area}

Nansi Lake (34 $27^{\prime}-35^{\circ} 20^{\prime} \mathrm{N}, 116^{\circ} 34^{\prime}-117^{\circ} 21^{\prime} \mathrm{E}$ ), a large freshwater lake and part of important storage and regulation works of the South-to-North Water Diversion Project (east route), lies in the southwestern part of Shandong Province, China. The entire catchment area covers $30.4 \times 10^{3} \mathrm{~km}^{2}$ with a surface area of $1.2 \times$
$10^{3} \mathrm{~km}^{2}$, and the average depth is $1.46 \mathrm{~m}$. Nansi Lake is connected with the sublakes of Nanyang, Dushan, Zhaoyang, and Weishan from north to south. After the construction of a dam located in the middle of Zhaoyang sublake in 1960, Nansi Lake was divided into an upper lake (northern part) and a lower lake (southern part) (Fig. 1). Three major urban settlements, Jining, Zaozhuang, and Heze, with populations of about 3.65, 7.97, and 8.19 million, respectively, form part of the Nansi Lake catchment. The eastern part of Weishan sublake lies close to National Highway 104, Jingtai Expressway, and Jing-Hu Railway.

\section{Sediments sampling}

Sixteen samples were collected (Fig. 1) from surface sediments $(0-5 \mathrm{~cm})$ of Nansi Lake in June 2012 using a gravity corer. Sites 1, 2, 3, 4, 5, 6 and 7 were in the lower lake, and others were in the upper lake. Then, the samples were sealed in plastic bags and taken to the laboratory. These samples were air-dried at room temperature $\left(25-28{ }^{\circ} \mathrm{C}\right)$, stones or other debris were removed, and then the samples were passed through a 2$\mathrm{mm}$ polyethylene sieve. Portions of all samples (about

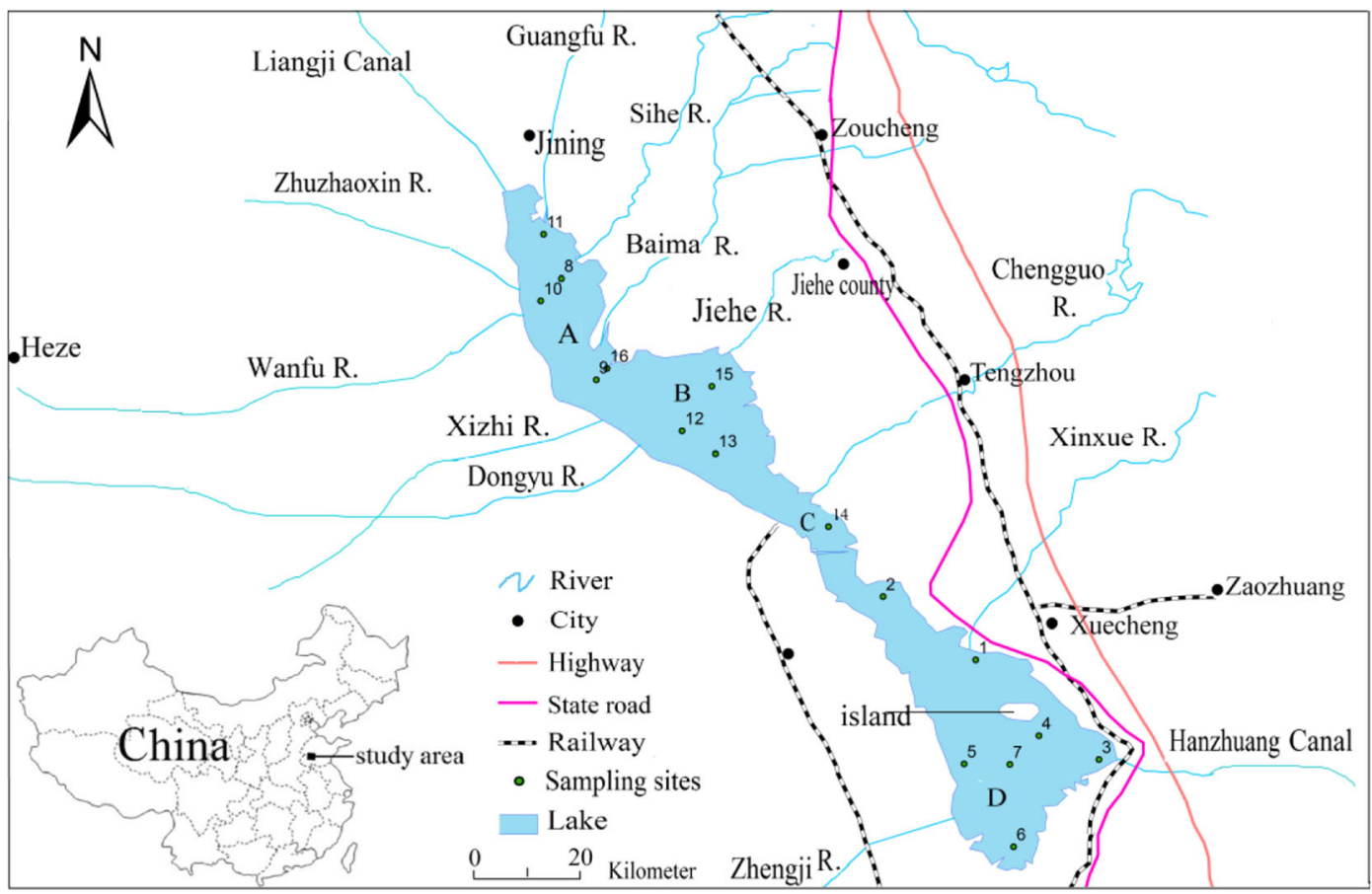

Fig. 1 Location of sampling sites in Nansi Lake. $A$, Nanyang sublake; $B$, Dushan sublake; $C$, Zhaoyang sublake; $D$, Weishan sublake 
$50 \mathrm{~g}$ ) were ground in an agate grinder and sieved through a $0.149-\mathrm{mm}$ mesh prior to chemical analysis.

Analytical methods

\section{Total concentration of heavy metals}

Subsamples of about $0.25 \mathrm{~g}$ were digested in Teflon vessels with a $\mathrm{HNO}_{3}$-HF- $\mathrm{HClO}_{4}$ mixture in a microwave oven. Then, after the sample solutions were filtered, the volume was adjusted to $25 \mathrm{ml}$ with double deionized water. The total concentrations of As were analyzed by an atomic fluorescence spectrometry (AFS, AFS-230E, Beijing, China), whereas $\mathrm{SiO}_{2}$ and $\mathrm{Cr}$ were measured by graphite furnace atomic absorption spectrometry (GF-AAS, M6, Thermo Elemental, Franklin, MA, USA), and the total concentrations of $\mathrm{Cd}, \mathrm{Zn}$, and $\mathrm{Pb}$ were measured by X-ray fluorescence spectrometry (XRF, ADVANT'XP, ARL, Switzerland). The major element $\mathrm{Si}$ was expressed as percent (\%) of metal oxides $\left(\mathrm{SiO}_{2}\right)$, while $\mathrm{Cr}, \mathrm{As}, \mathrm{Pb}, \mathrm{Zn}$, and $\mathrm{Cd}$ were expressed as milligrams per kilogram (Table 1). All analyses were completed in the lab of the Wuhan Inspection and Testing Center of Geology and Mineral Resources, of the Ministry of Land and Resources of China.

\section{Fractionation of heavy metals}

The seven-step extraction procedure recommended by Specification of Multi-purpose Regional Geochemical Survey (DD2005-03; CGS, 2005) was used to determine the fractionation of metals $(\mathrm{Cd}, \mathrm{As}, \mathrm{Pb}, \mathrm{Cr}$, and $\mathrm{Zn})$. Seven operationally defined fractions were determined for each metal: water soluble (F1), exchangeable fraction (F2), fraction bound to carbonate (F3), humic acid fraction (F4), reducible fraction (F5), strongly organic fraction (F6), and residual fraction (F7). All data reported are averaged values of three replicates. The sum of
Table 1 Content, background values, and pollution indices $\left(P_{\mathrm{i}}\right)$ of heavy metals in the surface sediments of Nansi Lake

\begin{tabular}{llllll}
\hline & $\mathrm{Cd}$ & $\mathrm{As}$ & $\mathrm{Pb}$ & $\mathrm{Cr}$ & $\mathrm{Zn}$ \\
\hline Mean & 0.21 & 15.38 & 26.93 & 76.44 & 91.64 \\
Min & 0.083 & 6.21 & 16.88 & 51.53 & 58.22 \\
Max & 0.39 & 28.86 & 36.72 & 88.78 & 121.32 \\
Background values & 0.077 & 7.5 & 15 & 60 & 90 \\
$P_{\mathrm{i}}$ (upper Nansi lake) & 1.94 & 1.55 & 1.56 & 1.2 & 0.91 \\
$P_{\mathrm{i}}$ (lower Nansi lake) & 3.85 & 2.70 & 2.10 & 1.37 & 1.16 \\
$P_{\mathrm{i}}$ (Nansi Lake) & 2.78 & 2.05 & 1.8 & 1.27 & 1.02 \\
\hline
\end{tabular}

F1, F2, F3, F4, F5, and F6 of a specific heavy metal is called the non-residual fraction. Of those, the sum of F1 and F2 is often considered the direct hazardous fraction because these fractions are easily absorbed by organisms and have strong mobility and reactivity in the environment (Kabala and Singh 2001; Waterlot et al. 2013; Zhong et al. 2011). The sum of F3, F4, F5, and F6 represents a potentially hazardous fraction under specific $\mathrm{pH}$ and redox conditions, and in that case, the metals will be soluble and can be absorbed by aquatic plants or ingested by animals causing environmental toxicity, creating a potential hazardous condition in the environment. The F7 fraction is held in the crystal lattice state of original mineral, so it is identified as the "inactive" fraction. Mostly, the F7 fraction is unavailable to either plants or microorganisms and presents no hazards to organisms (He et al. 2005; Ma and Rao 1997).

An internal check was performed on the results of the sequential extraction by comparing the total amount of metals extracted by different reagents during the sequential extraction procedure with the results of the total digestion (Yuan et al. 2004). The recovery of the sequential extraction was calculated using Eq. (1):

Recovery $=\left[\left(C_{\mathrm{F} 1}+C_{\mathrm{F} 2}+C_{\mathrm{F} 3}+C_{\mathrm{F} 4}+C_{\mathrm{F} 5}+C_{\mathrm{F} 6}+C_{\mathrm{F} 7}\right) / C_{\text {total digestion }}\right] \times 100$

Results indicated that the sum of the seven fractions is in good agreement with the total digestion results, with the satisfactory recovery rates (86.1-93.2\%).
Assessment of heavy metal pollution level

To assess the pollution level of heavy metals in the surface sediments, a pollution index $\left(P_{\mathrm{i}}\right)$ of each metal 
and pollution load index (PLI) of the studied metals were applied. The $\mathrm{P}_{\mathrm{i}}$, which is the ratio of heavy metal content in contaminated sediments to the content in uncontaminated sediments, provides a rapid and practical method that can be used to assess the pollution level:

$P_{\mathrm{i}}=C_{\text {heavy metal }} / C_{\text {background }}$

The $P_{\mathrm{i}}$ of each metal was classified as non-pollution $\left(P_{\mathrm{i}}<1\right)$ or as having a low $\left(1<P_{\mathrm{i}}<2\right)$, moderate $\left(2<P_{\mathrm{i}}<\right.$ $3)$, or high $\left(3<P_{\mathrm{i}}\right)$ level of pollution (Yu et al. 2004).

For the entire sampling sites, pollution load index (PLI) has been determined as the $n^{\text {th }}$ root of the product of $P_{\mathrm{i}}$ (Tomlinson et al. 1980) using Eq (3):

$\mathrm{PLI}=\left(P_{\mathrm{i} 1} \times P_{\mathrm{i} 2} \times P_{\mathrm{i} 3} \times \ldots \times P_{\mathrm{i} n}\right)^{1 / n}$

This PLI provides a simple, comparative means for assessing the level of heavy metal pollution, and the pollution load was then classified as no $(\mathrm{PLI}<1)$, moderate $(1<\mathrm{PLI}<2)$, heavy $(2<\mathrm{PLI}<3)$, or extremely heavy $(3<\mathrm{PLI})$ pollution.

\section{Statistical and spatial analyses}

Descriptive statistics and principal component analysis (PCA) were performed using SPSS v.16.0 (SPSS Inc., Chicago, USA). The heavy metal content was standardized through Z-scale transformation (whose mean and variance were set to zero and one, respectively) to avoid misclassification due to wide differences in data dimensionality (Varol 2011; Varol and Șen 2009). Moreover, prior to conducting PCA, Kaiser-Meyer-Olkin (KMO) and Bartlett's sphericity tests were used to examine its validity (Zhou et al. 2007). Results of Kaiser-MeyerOlkin $(\mathrm{KMO}=0.701)$ and Bartlett's sphericity tests $(P<0.05)$ indicated that heavy metal concentrations in surface sediments from Nansi Lake were suitable for PCA. In this study, all principal factors extracted from the variables explained $83.64 \%$ of the data variance. For the analysis of spatial variation, interpolation mapping was performed using the Ordinary Kriging method and ArcGIS 9.3 software (Environmental Systems Research Institute Inc., Redlands, CA, USA).

\section{Results and discussion}

Fractionation and bioavailability of heavy metals

The fractions estimated by the extraction method used in this study were represented as percentages of the total concentration in sediments (per portion) (Fig. 2a-e).

The fractionation results showed that $\mathrm{Cd}$ had the greatest $\mathrm{F} 1$ and $\mathrm{F} 2$ fractions of the studied heavy metals (Fig. 2a). It indicated that $\mathrm{Cd}$ had stronger mobility and reactivity in the surroundings than the other studied metals, and Cd may exert a direct hazard and threaten the lake's organisms. The highest F1 and F2 fractions for $\mathrm{Cd}$ appeared at sampling sites 9 and 15. It is probably because the Jiehe River received agricultural runoff which contained large amounts of phosphate fertilizers (Godt et al. 2006) and then flowed into Nansi Lake near site 15. Jiehe River flows through Jiehe County which is well known as China's largest potato planting area. Large numbers of phosphate fertilizers are applied during agricultural activities and most probably contain $\mathrm{Cd}$. $\mathrm{Cd}$ also had the greatest F3 fraction per portion (20.94 $\%)$ in the non-residual fractions, which indicated that an appreciable percentage of $\mathrm{Cd}$ would be likely to remobilize and become readily available if the $\mathrm{pH}$ was lowered slightly (Jain 2004). The highest F3 fraction per portion for Cd occurred at sampling sites 7 and 10, which are close to the farmlands, aquiculture areas, and inflow areas of tributaries.

As and $\mathrm{Pb}$ were in a group with a large proportion of the non-residual concentration present in the F4, F5, and F6 fractions (Fig. 2b, d). Negligible amounts of $\mathrm{Pb}$ and As were found in the F1 and F2 fractions compared to the total content, which reflected low mobility of these metals (Kabala and Singh 2001). The dominant proportion of As was found in the humic acid and reducible fractions among the non-residual fractions. This may be the result of their great abundance, specific surface area, and stronger binding affinity (Wang et al. 2012). A dominant proportion of $\mathrm{Pb}$ was found in the $\mathrm{F} 5$ fraction, in which $\mathrm{Pb}$ existed as oxides and may be released if the sediment was subjected to stronger reducing conditions (Panda et al. 1995). It indicated that As and $\mathrm{Pb}$ could become toxic in the environment and pose a potential environmental hazard, when the right $\mathrm{pH}$ and redox conditions were favorable. The highest F4 and F5 fractions for As occurred at 
Cd (a)

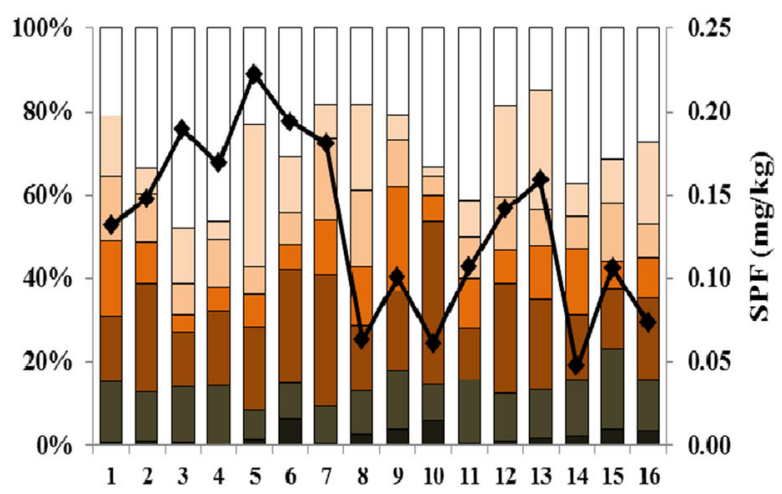

$\mathrm{Cr}(\mathrm{c})$

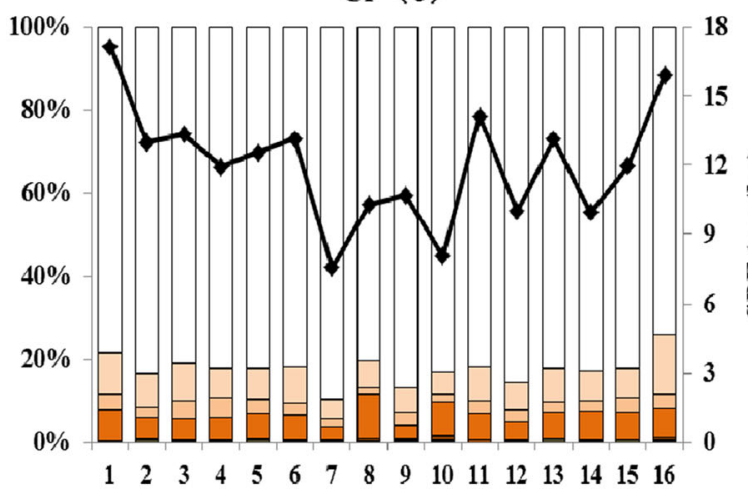

Zn (e)

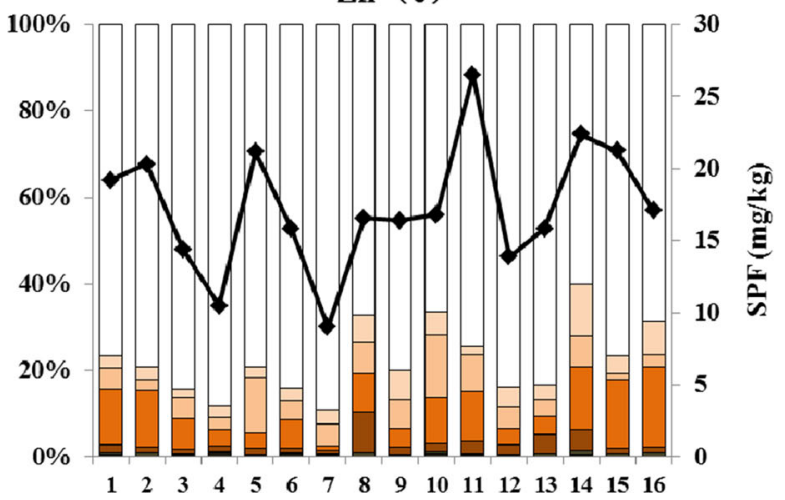

As（b)

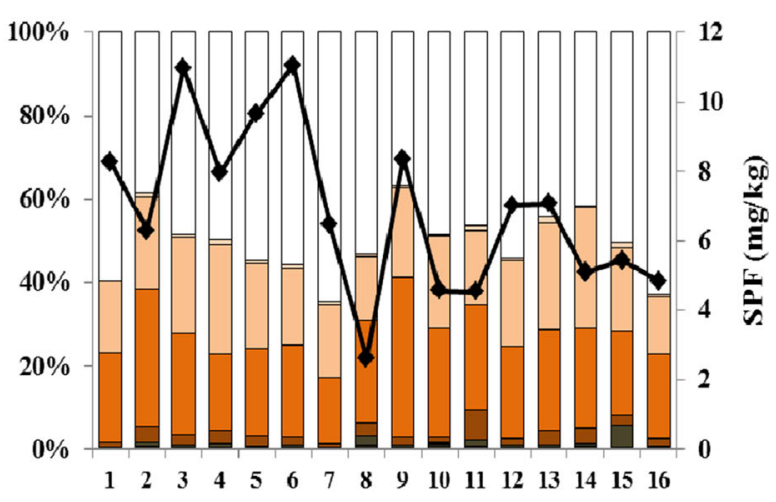

Fig. 2 a-e Percentage distribution of extracted metals after the seven-step sequential extraction procedure

sampling sites 2 and 9, while the highest F5 fraction for $\mathrm{Pb}$ appeared at sampling sites 3, 4, 6 , and 11. The non-residual fraction content of As and $\mathrm{Pb}$ were mainly higher than their background values in the lower lake (Fig. 2), which indicated the presence of anthropogenic inputs.

$\mathrm{Cr}$ and $\mathrm{Zn}$ mainly existed in the residual fraction (Fig. 2c, e, respectively), representing 74.26-89.74
$\%$ and $60.10-89.13 \%$ with an average of $82.37 \%$ and $77.61 \%$ of the total content, respectively. The low content of these two elements in the nonresidual fractions indicated that they were unlikely to pose a direct hazard or threaten the environment. Therefore, the relatively high content of the residual fraction for $\mathrm{Cr}$ and $\mathrm{Zn}$ might be beneficial from an environmental risk perspective. 
Pollution level of heavy metals

Table 1 listed the descriptive statistics (mean, min, and max) of the total content of heavy metals, together with their mean $P_{\mathrm{i}}$. Considering the Nansi Lake basin formation received sediments flushed from the Yellow River (Guo 1990; Shen et al. 2000), geochemical data from
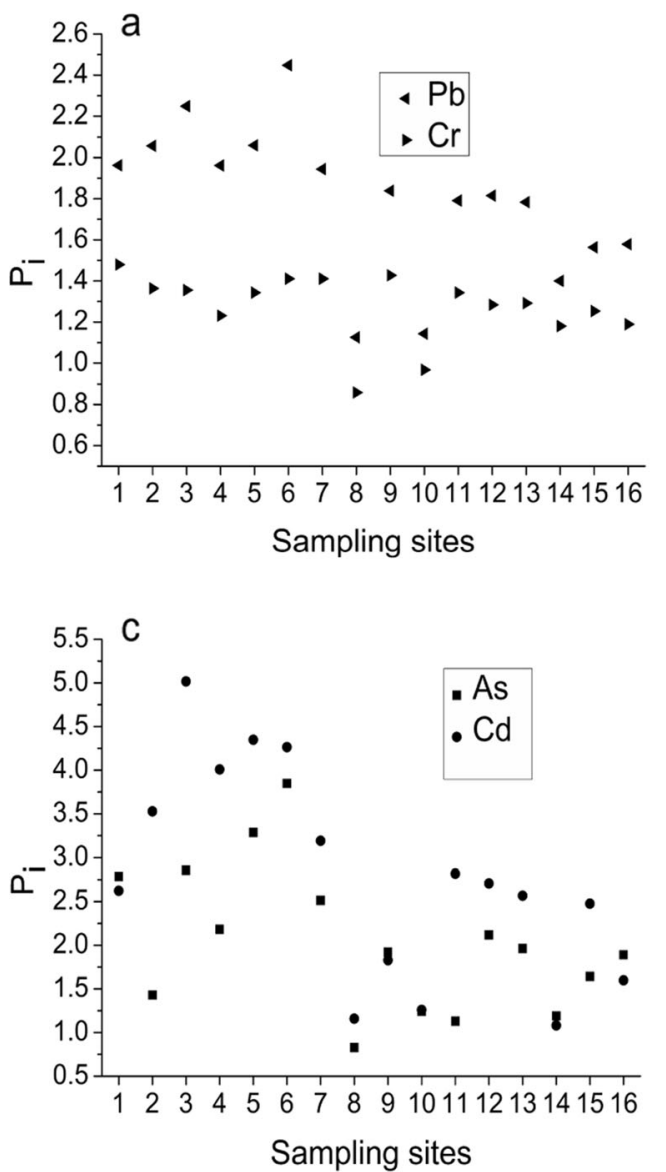

sediments in the main stream of the Yellow River (Zhang et al. 1998) were employed to act as background values for Nansi Lake. Figure 3 showed the $P_{\mathrm{i}}$ values of heavy metals, PLI values, and concentration of $\mathrm{SiO}_{2}$ in all sampling sites.

The results indicated that $\mathrm{Cd}, \mathrm{As}, \mathrm{Pb}, \mathrm{Cr}$, and $\mathrm{Zn}$ with $P_{\mathrm{i}}$ values of $2.78,2.05,1.80,1.27$, and 1.02 ,
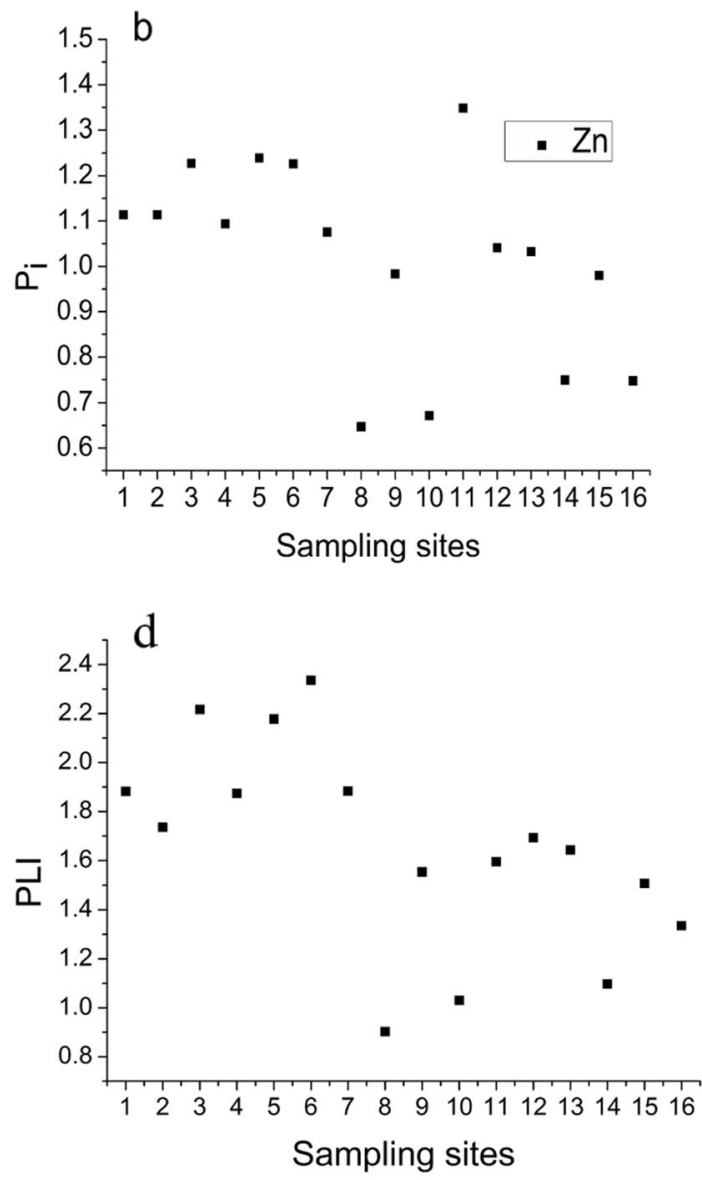

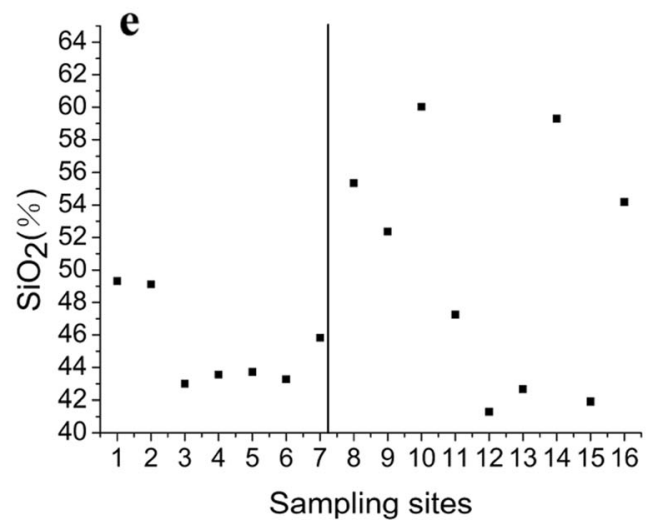

Fig. 3 a-e The pollution index $\left(P_{\mathrm{i}}\right), \mathrm{SiO}_{2}(\%)$ concentration, and pollution load index (PLI) for heavy metals in the Nansi Lake sampling sites 
respectively, revealed a moderate pollution level for $\mathrm{Cd}$ and $\mathrm{As}$ and a low pollution level for $\mathrm{Pb}, \mathrm{Cr}$, and $\mathrm{Zn}$. The lower lake had higher mean $P_{\mathrm{i}}$ for heavy metals especially $\mathrm{Cd}, \mathrm{As}$, and $\mathrm{Pb}$ than the upper lake, which indicated the sediments of the lower lake were more heavily polluted.

Figure $3 \mathrm{a}-\mathrm{c}$ showed that the $P_{\mathrm{i}}$ values of studied heavy metals in the upper lake sites were all below 2.0 except for As at sampling sites 9, 12, 13, and $\mathrm{Cd}$ at sampling sites $11,12,13$, and 15 . It is probably because sampling sites $9,11,12,13$, and 15 lie in the vicinity of the inflow areas of Guangfu, Xizhi, Dongyu, and Jiehe rivers, and the infusion of tributaries might bring many pollutants.

Figure $3 \mathrm{~d}$ showed that almost all PLI values calculated for sediments from the upper lake were above or close to 1.0, suggesting the surface sediments of the upper lake were moderately polluted by the heavy metals. Nevertheless, in the lower lake, the PLI values in surface sediments varied from 1.87 to 2.34 (mean= 2.06), indicating moderate to heavy pollution.

The $\mathrm{SiO}_{2}$ content in surface sediments of Nansi Lake was also analyzed. The lower lake had lower $\mathrm{SiO}_{2}$ content than the upper lake, although it fluctuated in Zhaoyang and Dushan sublakes (Fig. 3e). $\mathrm{SiO}_{2}$ is commonly considered the main component of coarse particles and heavy metals are likely to be absorbed by fine particles rather than by coarse particles (Salonen and Kirsti 2007; Wang and Cheng 2008), so the content of $\mathrm{SiO}_{2}$ is negatively related to the degree of enrichment of heavy metals in sediment. This idea is consistent with the pollution levels noted above for heavy metals.

Spatial distribution of non-residual fractions for heavy metals in surface sediments

The direct and potential hazards posed by heavy metals in surface sediments to the environment mostly depend on their non-residual fraction (Chen et al. 2008; Guevara-Riba et al. 2004). Therefore, PCA was performed to determine factors governing the spatial distribution of non-residual fractions of different heavy metals. Table 2 showed results of PCA with Z-scale normalization for the heavy metal non-residual fractions in surface sediments of Nansi Lake. Two principal components (PCs) with eigenvalues higher than 1.0 were extracted, which explained $83.64 \%$ of the variation in the data. The first principal component (PC1) explained $56.18 \%$ of the total variance and loaded heavily on $\mathrm{Cd}$
Table 2 Factor analysis for the non-residual fraction of heavy metals in the surface sediments of Nansi Lake

\begin{tabular}{lll}
\hline & PC1 & PC2 \\
\hline $\mathrm{Cd}$ & 0.93 & 0.006 \\
$\mathrm{As}$ & 0.90 & 0.13 \\
$\mathrm{~Pb}$ & 0.93 & 0.020 \\
$\mathrm{Cr}$ & 0.24 & 0.88 \\
$\mathrm{Zn}$ & -0.47 & 0.76 \\
Eigenvalue & 2.81 & 1.37 \\
Total variance (\%) & 56.18 & 27.46 \\
Cumulative variance (\%) & 59.18 & 83.64 \\
\hline
\end{tabular}

(0.93), As (0.90), and $\mathrm{Pb}$ (0.93), which suggested anthropogenic inputs. The second principal component (PC2), dominated by $\mathrm{Cr}(0.88)$ and $\mathrm{Zn}(0.76)$, accounted for $27.46 \%$ of the total variance and may be influenced by sediment parent materials.

The generated PC1 spatial distribution map of the non-residual fraction for heavy metals was obtained from the ArcGIS 9.3 with the Ordinary Kriging method (Fig. 4). The PC1 score decreased from north to south. The highest score zones, which indicated direct and potential hazards to the aquatic environment, were observed mostly in the southern part of Weishan sublake. This also indicated great

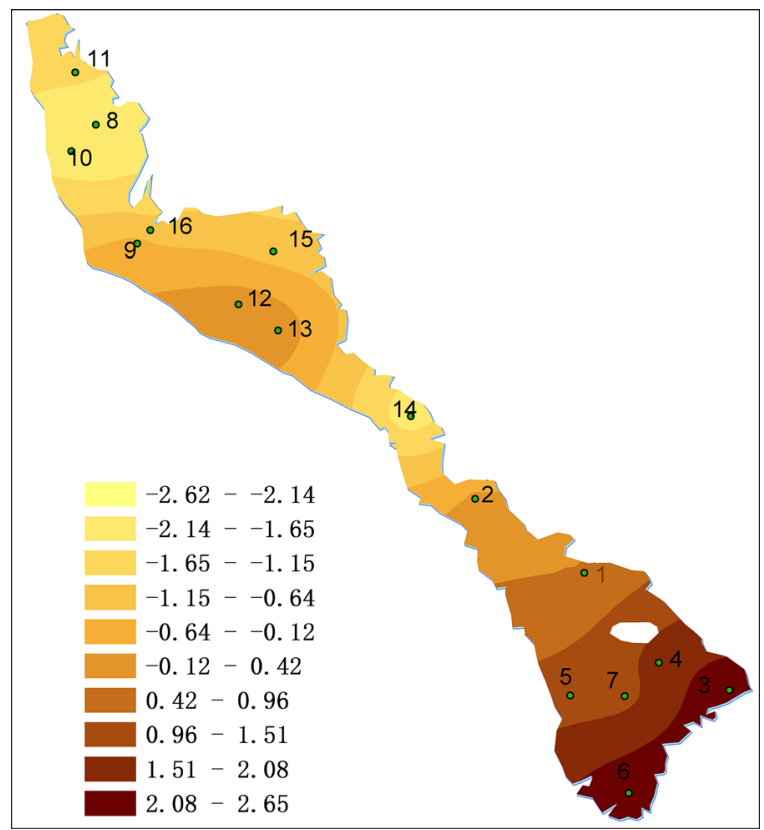

Fig. 4 PC1 spatial distribution map of the non-residual fraction for heavy metals 
bioavailability and toxicity of $\mathrm{Cd}, \mathrm{As}$, and $\mathrm{Pb}$ in this area. Weishan sublake is close to Hanzhuang Canal, which is navigable by ships of 1000 tons or even larger year-round, and is near National Highway 104, the Jingtai Expressway, and the Jing-Hu Railway, which always have dense traffic. Emissions from trains, boats, and cars can aggravate the pollution of $\mathrm{Pb}$ and $\mathrm{Cd}$ in waterways. Many farms and aquaculture areas exist in the area west of Weishan sublake. The phosphate fertilizer applied to agricultural lands most probably contains $\mathrm{Cd}$ and As. In addition, the lower lake suffered high levels of $\mathrm{Cd}$ pollution and moderate levels of $\mathrm{As}$ and $\mathrm{Pb}$ pollution, and the PLI also showed that the lower lake was moderately to heavily contaminated by the studied metals. Thus, the $\mathrm{Cd}, \mathrm{As}$, and $\mathrm{Pb}$ in surface sediments of the lower lake did great harm to the environment.

\section{Conclusion}

This study analyzed geochemical speciation of heavy metals including $\mathrm{Cd}, \mathrm{As}, \mathrm{Pb}, \mathrm{Cr}$, and $\mathrm{Zn}$, assessed their pollution level, and determined the spatial distribution of non-residual fraction. $\mathrm{Cd}$ had the greatest $\mathrm{F} 1$ and $\mathrm{F} 2$ fractions among values of all studied heavy metals, and $\mathrm{As}$ and $\mathrm{Pb}$ were mainly in the F4, F5, and F6 fractions, while the dominant fractions of $\mathrm{Cr}$ and $\mathrm{Zn}$ were $\mathrm{F} 7$ (more than $75 \%$ of the total content). The assessment results showed that the mean $P_{\mathrm{i}}$ value in the lower lake was higher than the upper lake. The pollution indices $\left(P_{\mathrm{i}}\right)$ of $\mathrm{Cd}$, $\mathrm{As}, \mathrm{Pb}, \mathrm{Cr}$, and $\mathrm{Zn}(2.73,2.05,1.80,1.27$, and 1.02, respectively) revealed a moderate level of $\mathrm{Cd}$ and As pollution and a low level of $\mathrm{Pb}, \mathrm{Cr}$, and $\mathrm{Zn}$ pollution. The calculated PLI values suggested that surface sediments were moderately polluted in the upper lake and moderately to heavily polluted in the lower lake by the heavy metals. The PC1 score decreased from north to south. The highest score zones, which indicated great bioavailability and toxicity of $\mathrm{Cd}, \mathrm{As}$, and $\mathrm{Pb}$, were observed mostly in the southern part of Weishan lake because of anthropogenic pollution.

Acknowledgments This research was financially supported by the Natural Science Foundation of Shandong Province (No.
ZR2012DL09) and the National Natural Science Foundation of China (No. 41271214, 40672076).

\section{References}

Chen, M., Li, X., Yang, Q., Zeng, G., Zhang, Y., Liao, D., et al. (2008). Total concentrations and speciation of heavy metals in municipal sludge from Changsha, Zhuzhou and Xiangtan in middle-south region of China. Journal of Hazardous Materials, 160(2), 324-329.

Feng, X. D., Dang, Z., Huang, W. L., \& Yang, C. (2009). Chemical speciation of fine particle bound trace metals. International Journal of Environmental Science and Technology, 6(3), 337-346.

Godt, J., Scheidig, F., Grosse-Siestrup, C., Esche, V., Brandenburg, P., Reich, A., et al. (2006). The toxicity of cadmium and resulting hazards for human health. Journal of Occupational Medicine and Toxicology, 1(22), 1-6.

Guevara-Riba, A., Sahuquillo, A., Rubio, R., \& Rauret, G. (2004). Assessment of metal mobility in dredged harbour sediments from Barcelona, Spain. Science of the Total Environment, 321(1), 241-255.

Guo, Y. (1990). On historical change of lakes in Shandong province. Transactions of Oceanology and Limnology, 3, 15-22.

He, Z. L., Yang, X. E., \& Stoffella, P. J. (2005). Trace elements in agroecosystems and impacts on the environment. Journal of Trace Elements in Medicine and Biology, 19(2), 125-140.

Jain, C. K. (2004). Metal fractionation study on bed sediments of River Yamuna, India. Water Research, 38(3), 569-578.

Kabala, C., \& Singh, B. R. (2001). Fractionation and mobility of copper, lead, and zinc in soil profiles in the vicinity of a copper smelter. Journal of Environmental Quality, 30(2), 485-492.

Karbassi, A. R., Bayati, I., \& Moattar, F. (2006). Origin and chemical partitioning of heavy metals in riverbed sediments. International Journal of Environmental Science and Technology, 3(1), 35-42.

Liu, H., Li, L., Yin, C., \& Shan, B. (2008). Fraction distribution and risk assessment of heavy metals in sediments of Moshui lake. Journal of Environmental Sciences, 20(4), 390-397.

Ma, L. Q., \& Rao, G. N. (1997). Chemical fractionation of cadmium, copper, nickel, and zinc in contaminated soils. Journal of Environmental Quality, 26(1), 259-264.

Panda, D., Subramanian, V., \& Panigrahy, R. C. (1995). Geochemical fractionation of heavy metals in Chilka Lake (east coast of India) - a tropical coastal lagoon. Environmental Geology, 26(4), 199-210.

Salonen, V., \& Kirsti, K. (2007). Influence of parent sediments on the concentration of heavy metals in urban and suburban soils in Turku, Finland. Applied Geochemistry, 22(5), 906-918.

Shen, J., Zhang, E., Zhang, Z., Sun, Q., \& Xia, W. (2000). A preliminary study on forming age of the Nansihu Lake. Journal of Lake Sciences, 12(1), 91-93.

Shrivastava, S. K., \& Banerjee, D. K. (2004). Speciation of metals in sewage sludge and sludge-amended soils. Water, Air, and Soil Pollution, 152(1-4), 219-232.

Tomlinson, D. L., Wilson, J. G., Harris, C. R., \& Jeffrey, D. W. (1980). Problems in the assessment of heavy-metal levels in 
estuaries and the formation of a pollution index. Helgoländer Meeresuntersuchungen, 33(1-4), 566-575.

Varol, M. (2011). Assessment of heavy metal contamination in sediments of the Tigris river (Turkey) using pollution indices and multivariate statistical techniques. Journal of Hazardous Materials, 195, 355-364.

Varol, M., \& Șen, B. (2009). Assessment of surface water quality using multivariate statistical techniques: a case study of Behrimaz stream, Turkey. Environmental Monitoring and Assessment, 159(1-4), 543-553.

Wang, H., \& Cheng, J. (2008). Geochemical characteristics of sediments deposited in the Dongdong cave and their environmental implication. Quaternary Sciences, 28(6), 1090-1097.

Wang, S. L., Lin, C. Y., Cao, X. Z., \& Zhong, X. (2012). Arsenic content, fractionation, and ecological risk in the surface sediments of lake. International Journal of Environmental Science and Technology, 9(1), 31-40.

Waterlot, C., Bidar, G., Pelfrêne, A., Roussel, H., Fourrier, H., \& Douay, F. (2013). Contamination, fractionation and availability of metals in urban soils in the vicinity of former lead and zinc smelters, France. Pedosphere, 23(2), 143-159.
Yu, L., Zhang, B., \& Zhang, S. (2004). Heavy metal elements pollution evaluation on the ecological environment of the Sanjiang Plain based on GIS. Chinese Journal of Soil Science, 35(5), 529-532.

Yuan, C., Shi, J., He, B., Liu, J., Liang, L., \& Jiang, G. (2004). Speciation of heavy metals in marine sediments from the East China Sea by ICP-MS with sequential extraction. Environment International, 30(6), 769-783.

Zhang, C., Zhang, S., \& Wang, L. (1998). Geochemistry of metals in sediments from Changiiang river and Huanghe river and their comparison. Acta Geographica Ainica, 53(4), 313-321.

Zhong, X., Zhou, S., Zhu, Q., \& Zhao, Q. (2011). Fraction distribution and bioavailability of soil heavy metals in the Yangtze river delta - a case study of Kunshan City in Jiangsu province, China. Journal of Hazardous Materials, 198, 13-21.

Zhou, F., Guo, H., \& Hao, Z. (2007). Spatial distribution of heavy metals in Hong Kong's marine sediments and their human impacts: a GIS-based chemometric approach. Marine Pollution Bulletin, 54(9), 1372-1384. 